\title{
Prescribing of oral anticoagulants in the emergency department and subsequent long- term use by older adults with atrial fibrillation
}

\author{
Clare L. Atzema MD MSc, Cynthia A. Jackevicius PharmD MSc, Alice Chong BSc, Paul Dorian MD MSc, \\ Noah M. Ivers MD PhD, Ratika Parkash MD MSc, Peter C. Austin PhD
}

Cite as: CMAJ 2019 December 9;191:E1345-54. doi: 10.1503/cmaj.190747

CMAJ Podcasts: author interview at https://soundcloud.com/cmajpodcasts/190747-res

\begin{abstract}
BACKGROUND: Patients with atrial fibrillation frequently seek emergency care. Rates of guideline-concordant oral anticoagulant therapy for stroke prevention are suboptimal in the community. We assessed the association between prescribing of oral anticoagulants in the emergency department (relative to referral to a longitudinal care provider for treatment initiation) and long-term use of oral anticoagulants.
\end{abstract}

METHODS: This retrospective cohort study performed at 15 hospitals in Ontario, Canada, involved patients aged 65 years or older who visited the emergency department between 2009 and 2014, who had a primary diagnosis of atrial fibrillation, were discharged home, and were eligible for and willing to take stroke-prevention therapy. We used inverse probability-of-treatment weighting based on the propensity score to compare patients who were and were not given a prescription for an oral anticoagulant. The primary outcome was a prescription fill for an oral anticoagulant 6 months later. Secondary outcomes included a prescription fill at 1 year, all-cause mortality, and strokes or bleeding events leading to hospital admission.

RESULTS: Of 2132 eligible patients, 402 (18.9\%) were given a prescription for an oral anticoagulant in the emergency department. After weighting, $67.8 \%$ of these patients had filled a prescription for an oral anticoagulant at 6 months versus $37.2 \%$ of those who did not receive a prescription in the emergency department (absolute risk increase [ARI] 30.6\%, number needed to treat [NNT] 3). At 1 year, the ARI was $23.2 \%$ and the NNT was 4. Rates of death, stroke and bleeding events did not differ significantly.

INTERPRETATION: In patients with atrial fibrillation who were eligible for stroke prevention, prescribing an oral anticoagulant in the emergency department was associated with substantially higher long-term use of oral anticoagulants compared with deferring to the longitudinal care provider to initiate this therapy. Physicians working in the emergency department should consider initiating oral anticoagulation in eligible patients who are being discharged to home.
$\mathrm{M}$ ore than 33 million people have atrial fibrillation worldwide, ${ }^{1}$ and the prevalence is expected to double in the coming decades. ${ }^{2,3}$ Atrial fibrillation is associated with a fivefold increase in the risk of stroke, ${ }^{4,5}$ for which the 1-year mortality rate is $50 \%{ }^{6}$ Stroke prevention with oral anticoagulation therapy decreases the risk by about $60 \%, 7,8$ and numerous guidelines endorse this type of therapy for high-risk patients with atrial fibrillation. ${ }^{9-11}$ Nonetheless, many studies have documented suboptimal use of oral anticoagulants. ${ }^{12-14}$

Patients with atrial fibrillation often present to the emergency department because of symptoms such as palpitations, shortness of breath and chest pain. ${ }^{15,16}$ In Ontario, there are about 20000 emergency department visits per year for atrial fibrillation, and most of these patients (63\%) are sent home after emergency care (v. $31 \%$ in the United States). ${ }^{17}$ Therefore, the emergency department may be an important setting for improvement of suboptimal prescribing rates for oral anticoagulants. ${ }^{18-20}$ The advent of direct oral anticoagulants, ${ }^{21-24}$ which do not require bridging or monitoring of the international normalized ratio, may improve the willingness of emergency physicians to initiate a long-term medication that may cause bleeding. However, current usual care is referral to the longitudinal care provider (e.g., primary care provider or cardiologist) to initiate such medications, as that provider will have the patient's complete medical history, can follow the patient for potential adverse effects and dose adjustments, and has more time for shared decision-making, possibly over more than 1 visit. ${ }^{25,26}$ In addition, there are limited data on whether initiation of oral anticoagulants in the emergency department results in greater long-term use. ${ }^{27}$

We assessed the long-term use of oral anticoagulants after provision of a prescription in the emergency department, compared with deferral to the longitudinal health care provider for initiation of therapy. 


\section{Methods}

\section{Study design}

This retrospective cohort study was performed at 15 emergency departments (listed in Appendix 1, Table A1, available at www. cmaj.ca/lookup/suppl/doi:10.1503/cmaj.190747/-/DC1) in Ontario, Canada, with linkage to province-wide health data sets.

\section{Data sources and data collection}

We identified potential study patients from the National Ambulatory Care Reporting System of the Canadian Institute for Health Information, which collects data on all emergency department visits in Ontario. ${ }^{28}$ Because the data set does not include information about provision of prescriptions, a trained physician abstracted the identified charts at each hospital. This allowed confirmation that, for all patients, atrial fibrillation (code 1480) had been diagnosed in the emergency department. ${ }^{18}$ The abstractor collected chart data using standardized definitions. Chart data were linked at ICES (via unique, encoded identifiers) to numerous databases containing the following Ontario-wide data: hospital admissions, mortality (including out-of-hospital deaths), instances of filling a prescription for an anticoagulant, billings by any physician and physician specialty (Appendix 1, Table A2). ${ }^{29-32}$

\section{Study participants}

Patients eligible for inclusion were those aged 65 years or older who were seen between Apr. 1, 2009, and Mar. 31, 2014, and were discharged home from the emergency department with a primary diagnosis of atrial fibrillation/flutter (i.e., the first diagnosis written on the chart by the managing physician). Thus, we included both incident and prevalent cases of atrial fibrillation. Because age 65 years or older was a qualifying criterion for use of oral anticoagulants in the 2014 Canadian guidelines for atrial fibrillation (based on the CHADS-65 algorithm),,$^{33}$ all of these patients qualified for this therapy. We excluded patients who were already taking these drugs (i.e., prescription fill within the previous $90 \mathrm{~d}$ ) and those whose international normalized ratio was greater than 1.2. A physician's reluctance to prescribe for patients perceived to be at higher risk for bleeding or a patient's resistance to taking an anticoagulant might affect both emergency department prescribing and the primary outcome measure (subsequent prescribing). Therefore, we excluded patients with relative contraindications to oral anticoagulants or the potential for clinician perception of a high risk of bleeding, specifically those from a nursing home and those with a history of major cancer, hemorrhagic stroke, major gastrointestinal bleeding or HAS-BLED score of 4 or higher, ${ }^{34}$ as well as cases in which the managing physician documented patient refusal.

The exposure group consisted of patients who received a prescription for an oral anticoagulant in the emergency department ("emergency department prescription group"), and the nonexposed group consisted of those who did not receive a prescription ("no emergency department prescription group").

\section{Outcome measures}

The primary outcome measure was a prescription fill for an oral anticoagulant at 6 months after the emergency visit. Prescriptions in Ontario can have a maximum duration of 100 days to be eligible for payment by the Ontario Drug Benefit Program, so we defined our outcome measure as a prescription fill between 130 and 230 days after discharge. Medications included in the analysis were warfarin, apixaban, dabigatran and rivaroxaban; at the time of the study, edoxaban had not yet been approved in Canada. Secondary outcomes included a prescription fill for an oral anticoagulant at 1 year (315-415 d after discharge), all-cause mortality, and stroke (hemorrhagic or ischemic) or bleeding event leading to hospital admission. Strokes and bleeding events (gastrointestinal, genitourinary or respiratory bleeding; intracranial hemorrhage) were determined using the Discharge Abstract Database (codes listed in Appendix 1, Table A3). ${ }^{35}$ Adherence to anticoagulant therapy was defined as $80 \%$ or higher, and discontinuation was defined as a gap in medication fill of 30 days or more.

\section{Statistical analysis}

Univariable comparisons between exposure groups were performed using $\chi^{2}$ and $t$ tests, as appropriate. The proportion of days covered by oral anticoagulant therapy was calculated for each group at 30, 90, 180 and 365 days. All patients were eligible for stroke prevention with an oral anticoagulant; however, we adjusted for differences between groups using inverse probabilityof-treatment weighting based on the propensity score. This increases the likelihood that we were comparing 2 groups with a similar distribution of baseline covariables that might influence prescribing of oral anticoagulants both in the emergency department and in follow-up (i.e., covariables related to perceived bleeding risk). Using patients who were alive at the time of outcome assessment (to avoid immortal time bias $^{36}$ ), we estimated a propensity score by regressing prescription provision on 29 variables selected a priori. ${ }^{15,27,37}$ This method weights participants by the inverse of the probability of actual treatment received. ${ }^{38}$ Balance between groups was assessed using weighted standardized differences. ${ }^{39}$ We calculated absolute risk differences between groups, as well as numbers needed to treat (NNTs).

We performed the following sensitivity analyses. We used logistic regression in the unweighted sample for prescription fill outcomes. We repeated the inverse-weighting analysis in a cohort without exclusions based on HAS-BLED score, ${ }^{34}$ because that score was not meant to prevent physicians from initiating oral anticoagulants, but rather to address risk factors for bleeding (which an emergency physician is in no position to do on a continuing basis). ${ }^{10,11}$ We performed the analysis for only those patients with electrocardiographic (ECG) or rhythmstrip proof of atrial fibrillation in the chart.

All analyses were performed with SAS software (version 9.3).

\section{Ethics approval}

Ethics approval was obtained from the pertinent research ethics boards of all sites, as listed in Appendix 1, Table A1.

\section{Results}

Of 2132 eligible patients, 402 (18.9\%) had chart documentation that an oral anticoagulant prescription had been provided in the emergency department (Table 1). Of these prescriptions, 
Table 1 (part 1 of 2): Characteristics of patients who did and did not receive an oral anticoagulant (OAC) prescription in the emergency department

\begin{tabular}{|c|c|c|c|}
\hline \multirow[b]{2}{*}{ Characteristic } & \multicolumn{3}{|c|}{ Group; no. (\%) of patients* } \\
\hline & $\begin{array}{c}\text { All } \\
n=2132\end{array}$ & $\begin{array}{l}\text { Received OAC } \\
\text { prescription } \\
n=402\end{array}$ & $\begin{array}{l}\text { Did not receive } \\
\text { OAC prescription } \\
\qquad n=1730\end{array}$ \\
\hline \multicolumn{4}{|l|}{ Patient } \\
\hline \multicolumn{4}{|l|}{ Age, yr } \\
\hline Mean \pm SD & $75.9 \pm 7.3$ & $77.2 \pm 6.8$ & $75.7 \pm 7.3$ \\
\hline Median (IQR) & $75.0(70.0-81.0)$ & $77.0(72.0-82.0)$ & $75.0(70.0-81.0)$ \\
\hline Sex, female & $1256(58.9)$ & $216(53.7)$ & $1040(60.1)$ \\
\hline Rural residence & $45(2.1)$ & $13(3.2)$ & $32(1.8)$ \\
\hline \multicolumn{4}{|l|}{ Income quintile } \\
\hline 1 (lowest) & $302(14.2)$ & $59(14.7)$ & $243(14.0)$ \\
\hline 2 & $380(17.8)$ & $69(17.2)$ & $311(18.0)$ \\
\hline 3 & $418(19.6)$ & 76 (18.9) & $342(19.8)$ \\
\hline 4 & $533(25.0)$ & $96(23.9)$ & $437(25.3)$ \\
\hline 5 (highest) & $499(23.4)$ & $102(25.4)$ & $397(22.9)$ \\
\hline Came from doctor's office (v. home) & $569(26.7)$ & $159(39.6)$ & $410(23.7)$ \\
\hline \multicolumn{4}{|l|}{ Medical history } \\
\hline Atrial fibrillation & $568(26.6)$ & $66(16.4)$ & $502(29.0)$ \\
\hline Heart failure & $224(10.5)$ & $47(11.7)$ & $177(10.2)$ \\
\hline Hypertension & $1615(75.8)$ & $332(82.6)$ & $1283(74.2)$ \\
\hline Diabetes mellitus & $385(18.1)$ & 87 (21.6) & $298(17.2)$ \\
\hline Stroke or TIA & $23(1.1)$ & $\dagger$ & $\dagger$ \\
\hline Coronary artery disease & $421(19.7)$ & $84(20.9)$ & $337(19.5)$ \\
\hline Valvular disease & $36(1.7)$ & $10(2.5)$ & $26(1.5)$ \\
\hline Chronic obstructive pulmonary disease & $131(6.1)$ & $27(6.7)$ & $104(6.0)$ \\
\hline Chronic renal failure & $30(1.4)$ & $7(1.7)$ & $23(1.3)$ \\
\hline Dementia & $40(1.9)$ & $8(2.0)$ & $32(1.8)$ \\
\hline History of falls & $41(1.9)$ & $9(2.2)$ & $32(1.8)$ \\
\hline ADG score, median (IQR) & $13(10-15)$ & $12(10-15)$ & $13(10-15)$ \\
\hline \multicolumn{4}{|l|}{$\mathrm{CHADS}_{2}$ score } \\
\hline 0 & $216(10.1)$ & $19(4.7)$ & $197(11.4)$ \\
\hline 1 & $780(36.6)$ & $112(27.9)$ & $668(38.6)$ \\
\hline 2 & $812(38.1)$ & $196(48.8)$ & $616(35.6)$ \\
\hline$\geq 3$ & $324(15.2)$ & $75(18.7)$ & $249(14.4)$ \\
\hline \multicolumn{4}{|l|}{$\mathrm{CHA}_{2} \mathrm{DS}_{2}$-VASc score } \\
\hline 1 & $97(4.5)$ & $7(1.7)$ & $90(5.2)$ \\
\hline 2 & $384(18.0)$ & $57(14.2)$ & $327(18.9)$ \\
\hline 3 & $681(31.9)$ & $118(29.4)$ & $563(32.5)$ \\
\hline 4 & $611(28.7)$ & $149(37.1)$ & $462(26.7)$ \\
\hline 5 & $260(12.2)$ & $57(14.2)$ & $203(11.7)$ \\
\hline$\geq 6$ & $99(4.6)$ & $14(3.5)$ & $85(4.9)$ \\
\hline HAS-BLED score 1 or 2 (v. 3) & $942(44.2)$ & $179(44.5)$ & $763(44.1)$ \\
\hline Warfarin therapy failed in the past & $9(0.4)$ & $0(0.0)$ & $9(0.5)$ \\
\hline History of GI bleed & $19(0.9)$ & $\dagger$ & $\dagger$ \\
\hline
\end{tabular}


Table 1 (part 2 of 2): Characteristics of patients who did and did not receive an oral

anticoagulant (OAC) prescription in the emergency department

\begin{tabular}{|c|c|c|c|}
\hline \multirow[b]{2}{*}{ Characteristic } & \multicolumn{3}{|c|}{ Group; no. (\%) of patients* } \\
\hline & $\begin{array}{c}\text { All } \\
n=2132\end{array}$ & $\begin{array}{c}\text { Received OAC } \\
\text { prescription } \\
n=402\end{array}$ & $\begin{array}{l}\text { Did not receive } \\
\text { OAC prescription } \\
\qquad n=1730\end{array}$ \\
\hline History of other bleed & $10(0.5)$ & $0(0.0)$ & $10(0.6)$ \\
\hline \multicolumn{4}{|l|}{ Smoking history } \\
\hline Current & $83(3.9)$ & $10(2.5)$ & $73(4.2)$ \\
\hline Previous & $138(6.5)$ & $35(8.7)$ & $103(6.0)$ \\
\hline ASA & 775 (36.4) & $147(36.6)$ & $628(36.3)$ \\
\hline Clopidogrel & $44(2.1)$ & $8(2.0)$ & $36(2.1)$ \\
\hline ASA + clopidogrel ${ }^{40}$ & $50(2.3)$ & $6(1.5)$ & $44(2.5)$ \\
\hline \multicolumn{4}{|l|}{ ED arrival and care } \\
\hline Arrival by ambulance & $581(27.3)$ & $78(19.4)$ & $503(29.1)$ \\
\hline \multicolumn{4}{|l|}{ Triage score $\ddagger$} \\
\hline 1 or 2 & $426(20.0)$ & $96(23.9)$ & $330(19.1)$ \\
\hline 3,4 or 5 & $1706(80.0)$ & $306(76.1)$ & $1400(80.9)$ \\
\hline Presenting heart rate, median (IQR) & $113(88-136)$ & $110(85-132)$ & $114(89-138)$ \\
\hline $\begin{array}{l}\text { Proof of atrial fibrillation by ECG or } \\
\text { rhythm strip }\end{array}$ & $1949(91.4)$ & $389(96.8)$ & $1560(90.2)$ \\
\hline Creatinine, $\mu \mathrm{mol} / \mathrm{L}$, median (IQR) & $82(68-98)$ & $87(72-103)$ & $81(68-97)$ \\
\hline \multicolumn{4}{|l|}{ Discharge } \\
\hline \multicolumn{4}{|l|}{ Discharge rhythm } \\
\hline Normal sinus rhythm & $1142(53.6)$ & $93(23.1)$ & $1049(60.6)$ \\
\hline Atrial fibrillation & $875(41.0)$ & $274(68.2)$ & $601(34.7)$ \\
\hline Other & $95(4.5)$ & $30(7.5)$ & $65(3.8)$ \\
\hline Unknown & $20(0.9)$ & $\dagger$ & $\dagger$ \\
\hline New prescription of ASA and/or clopidogrel & $380(17.8)$ & $\dagger$ & $\dagger$ \\
\hline ED physician prescribed OAC & $296(13.9)$ & $296(73.6)$ & - \\
\hline $\begin{array}{l}\text { ED physician documented that prescribing } \\
\text { OAC was considered }\end{array}$ & $308(14.4)$ & $\dagger$ & $\dagger$ \\
\hline $\begin{array}{l}\text { Consultation provided by cardiologist or } \\
\text { internist in } E D\end{array}$ & $341(16.0)$ & $106(26.4)$ & $235(13.6)$ \\
\hline \multicolumn{4}{|l|}{ Documented follow-up advice } \\
\hline $\begin{array}{l}\text { Follow up with relevant provider (PCP, } \\
\text { cardiologist, internist) }\end{array}$ & $1952(91.6)$ & $386(96.0)$ & $1566(90.5)$ \\
\hline Follow up with other provider & $39(1.8)$ & $12(3.0)$ & $27(1.6)$ \\
\hline \multicolumn{4}{|c|}{$\begin{array}{l}\text { Note: } A D G=\text { Adjusted Diagnostic Group }{ }^{41} \mathrm{ASA}=\text { acetylsalicylic acid, ECG }=\text { electrocardiogram, } E D=\text { emergency department, } \\
\mathrm{GI}=\text { gastrointestinal, } \mathrm{IQR}=\text { interquartile range, } \mathrm{PCP}=\text { primary care provider, } \mathrm{SD}=\text { standard deviation, } \mathrm{TIA}=\text { transient ischemic attack. } \\
\text { "Except where indicated otherwise. } \\
\text { tOwing to a privacy agreement between the Canadian Institute for Health Information and ICES, these data values are not reported } \\
\text { either because } n \leq 5 \text {, or to prevent the calculation of values } \leq 5 . \\
\text { †According to Canadian Triage and Acuity Score. }{ }^{42}\end{array}$} \\
\hline
\end{tabular}

296 (73.6\%) were written by the managing emergency physician, not a consulting physician (Appendix 1, Table A4). The prescribing rate varied widely across hospitals (7.3\%-38.2\%). For more than $90 \%$ of all patients, an instruction to follow up with a relevant provider was documented in the chart.

In univariable analyses, 280 (71.8\%) of the 390 patients who received an emergency department prescription for an oral anticoagulant and were alive at 6 months filled a prescription at 6 months (Table 2). Among the 1672 patients who were discharged without a prescription and were still alive at 6 months, 615 (36.8\%) filled a prescription for an oral anticoagulant at 6 months. In the emergency department prescription group, $75.1 \%$ (302/402) had an outpatient physician visit within 7 days, and 96.3\% (387/402) had such a visit by 30 days (Table 3), compared with 57.5\% (994/1730) 


\begin{tabular}{lccc} 
Outcome & $\begin{array}{c}\text { All } \\
\boldsymbol{n}=\mathbf{2 1 3 2}\end{array}$ & $\begin{array}{c}\text { Received OAC prescription } \\
\boldsymbol{n}=\mathbf{4 0 2}\end{array}$ & $\begin{array}{c}\text { Did not receive OAC presc } \\
\boldsymbol{n}=\mathbf{1 7 3 0}\end{array}$ \\
$\begin{array}{l}\text { Prescriptions for OAC } \\
\text { At } 6 \text { mo (130-230 d after discharge) }\end{array}$ & $280(69.7)$ & $12(3.0)$ & $615(35.5)$ \\
\hline Filled prescription for OAC & $895(42.0)$ & $58(3.4)$ \\
\hline Died & $70(3.3)$ & $261(64.9)$ & $23(5.7)$ \\
\hline At 1 yr (315-415 d after discharge) & & & $673(38.9)$ \\
\hline Filled prescription for OAC & $934(43.8)$ & $87(5.0)$ \\
\hline Died & $110(5.2)$ & $355(88.3)$ & $795(46.0)$ \\
\hline Filled $\geq 1$ prescription for OAC up to $1 \mathrm{yr}(415 \mathrm{~d})$ after ED visit & & $1(0-1)$ & $28(7-100)$ \\
\hline No. (\%) of patients & $1150(53.9)$ & $12 \pm 46$ & $76 \pm 103$ \\
\hline Time to first fill, median (IQR) & $10(1-61)$ & $56 \pm 94$ &
\end{tabular}

\section{Discontinuation of OAC therapy}

Filled $\geq 1$ prescription within $180 \mathrm{~d}$, but discontinued before $d 230$

\section{Discontinued $\dagger$ \\ No discontinuation}

Filled $\geq 1$ prescription within $365 \mathrm{~d}$, but discontinued before $\mathrm{d} 415$

\section{Discontinued $\dagger$ \\ No discontinuation}

\section{Secondary outcomes}

Death

$\begin{array}{lc}30 \mathrm{~d} & 9(0.4) \\ 90 \mathrm{~d} & 33(1.5) \\ 180 \mathrm{~d} & 58(2.7) \\ 1 \mathrm{yr} & 99(4.6) \\ 2 \mathrm{yr} & 176(8.3)\end{array}$

Stroke, any type

$180 \mathrm{~d}$

$1 \mathrm{yr}$

$2 \mathrm{yr}$

Bleeding event

$180 \mathrm{~d}$

$1 \mathrm{yr}$

$2 \mathrm{yr}$
$427 / 1035(41.3)$

\section{$168 / 355(47.3)$}

$187 / 355(52.6)$

$259 / 680$ (38.1)

$421 / 680$ (61.9)

24 (1.1)

$44(2.1)$

$16(0.8)$

$27(1.3)$

$44(2.1)$

\section{$\ddagger$}

8 (2.0)

$10(2.5)$

$19(4.7)$

$35(8.7)$

\section{$\ddagger$}

$6(1.5)$

7 (1.7)

$6(1.5)$

$9(2.2)$

$13(3.2)$

Note: $\mathrm{IQR}=$ interquartile range, $\mathrm{SD}=$ standard deviation

*Except where noted otherwise.

†Denominator shown excludes patients who died and those who did not fill a prescription for OAC within the specified time frame.

fOwing to a privacy agreement between the Canadian Institute for Health Information and ICES, these data values are not reported either because $n \leq 5$, or to prevent the calculation of values $\leq 5$

and $88.3 \%$ (1528/1730), respectively, among the no emergency department prescription group. Patients who were given a prescription for an oral anticoagulant in the emergency department filled it a median of 1 day after discharge (mean $12 \mathrm{~d}$; Table 2). Among those in the no-prescription group who actually filled a pre- scription at some point during the 1-year follow-up (46.0\%), median time to fill the prescription was 28 days (mean $76 \mathrm{~d}$ ).

After inverse probability-of-treatment weighting, the groups were well balanced, ${ }^{38}$ other than slightly more patients in the highestincome quintile in the emergency department prescription group 
(Appendix 1, Table A5). After weighting, the proportions who filled a prescription for an oral anticoagulant at 6 months were $67.8 \%$ in the emergency department prescription group and $37.2 \%$ in the no- prescription group (absolute risk increase [ARI] 30.6\%, NNT 3) (Table 4). At 1 year, the corresponding proportions were $63.7 \%$ and $40.5 \%$, respectively (ARI 23.2 , NNT 4).

In the sensitivity analyses using logistic regression, the adjusted odds for a prescription fill at 6 months for the emergency department prescription group relative to the no-prescription group were 3.26 (95\% Cl 2.66-4.01), and the adjusted odds at 1 year were 2.37 (95\% Cl 1.86-3.02). Results were similar for the cohort without HAS-BLED score exclusions and for patients with ECG or rhythmstrip proof of atrial fibrillation documented in the chart.

In the 30 days after discharge, adherence (based on proportion of days covered) was $74.6 \%$ in the emergency department prescription group and $14.0 \%$ in the no-prescription group (Figure 1). By 6 months, adherence was $60.2 \%$ and $21.7 \%$, respectively, and at 1 year, it had fallen to $56.0 \%$ in the emergency department prescription group and $24.3 \%$ in the no-prescription group. At all time points, those in the emergency department prescription group had a higher proportion of days covered than those in the no-prescription group. Discontinuations are shown in Table 2 and Appendix 1, Figure A1.

Among the 1296 patients who obtained 7-day outpatient followup care, $39.0 \%$ (83/213) of those who saw a cardiologist filled a prescription for an oral anticoagulant within 30 days of that appointment: $62.5 \%$ (25/40) in the emergency department prescription group and $33.5 \%$ (58/173) in the no-prescription group (Table 3) (ARI 29.0\%). Among patients who saw an internist, the ARI was $34.1 \%$. Most patients who obtained 7-day follow-up saw a primary care provider (66.0\% [855/1296]), and 61.1\% (135/221) of the emergency department prescription group filled an oral anticoagulant prescription within 30 days of the appointment compared with $22.2 \%$ (141/634) of the no-prescription group (ARI 38.9\%).

Strokes leading to hospital admission were uncommon in both groups (Table 2), and most were ischemic. After inverse weighting, the absolute event rates for death and for strokes were not statistically different between groups (Appendix 1, Table A6). Bleeding events were not statistically different at any follow-up time, including after weighting.

\section{Table 3: Univariable results for type of follow-up care in relation to receipt of an oral anticoagulant} (OAC) prescription in the emergency department

\begin{tabular}{|c|c|c|c|}
\hline \multirow[b]{2}{*}{ Outcome } & \multicolumn{3}{|c|}{ Group; no. (\%) of patients } \\
\hline & $\begin{array}{c}\text { All } \\
n=2132\end{array}$ & $\begin{array}{c}\text { Received } \\
\text { OAC prescription } \\
n=402\end{array}$ & $\begin{array}{l}\text { Did not receive } \\
\text { OAC prescription } \\
\qquad n=1730\end{array}$ \\
\hline \multicolumn{4}{|c|}{ Follow-up care within $7 \mathrm{~d}$} \\
\hline No. (\%) of patients & $1296(60.8)$ & $302(75.1)$ & $994(57.5)$ \\
\hline \multicolumn{4}{|c|}{ Specialty of first follow-up } \\
\hline Cardiology & $213(10.0)$ & $40(10.0)$ & $173(10.0)$ \\
\hline Internal medicine & $228(10.7)$ & $41(10.2)$ & $187(10.8)$ \\
\hline Family medicine & $855(40.1)$ & $221(55.0)$ & $634(36.6)$ \\
\hline No follow-up & $836(39.2)$ & $100(24.9)$ & $736(42.5)$ \\
\hline \multicolumn{4}{|c|}{ Filled prescription for OAC within $30 \mathrm{~d}$ of follow-up* } \\
\hline Cardiology & $83 / 213(39.0)$ & $25 / 40(62.5)$ & $58 / 173(33.5)$ \\
\hline Internal medicine & $92 / 228(40.4)$ & $28 / 41(68.3)$ & $64 / 187(34.2)$ \\
\hline Family medicine & $276 / 855(32.3)$ & $135 / 221(61.1)$ & $141 / 634(22.2)$ \\
\hline \multicolumn{4}{|c|}{ Follow-up care within $30 \mathrm{~d}$} \\
\hline No. (\%) of patients & $1915(89.8)$ & $387(96.3)$ & $1528(88.3)$ \\
\hline \multicolumn{4}{|c|}{ Specialty of first follow-up } \\
\hline Cardiology & $392(18.4)$ & $57(14.2)$ & $335(19.4)$ \\
\hline Internal medicine & $292(13.7)$ & $54(13.4)$ & $238(13.8)$ \\
\hline Family medicine & $1231(57.7)$ & $276(68.7)$ & $955(55.2)$ \\
\hline No follow-up & $217(10.2)$ & $15(3.7)$ & $202(11.7)$ \\
\hline \multicolumn{4}{|c|}{ Filled prescription for OAC within $30 \mathrm{~d}$ of follow-up* } \\
\hline Cardiology & $135 / 392(34.4)$ & $32 / 57(56.1)$ & $103 / 335(30.7)$ \\
\hline Internal medicine & $109 / 292(37.3)$ & $32 / 54(59.3)$ & $77 / 238(32.4)$ \\
\hline Family medicine & $357 / 1231(29.0)$ & $162 / 276(58.7)$ & $195 / 955(20.4)$ \\
\hline
\end{tabular}




\section{Interpretation}

In this multicentre study in Ontario, Canada, providing an oral anticoagulant prescription in the emergency department to patients with atrial fibrillation who were older than 65 years was associated with a marked increase in long-term use of this therapy. The NNT for 1 additional patient to fill a prescription for an oral anticoagulant at 6 months after the emergency visit was 3. The NNT had increased to 4 by 1 year, which was expected because persistence with this therapy is known to decline over time. ${ }^{43,44}$ To prevent 1 stroke at 1 year, the NNT with oral anticoagulants is $1.7 ;^{7}$ therefore, the NNT for oral anticoagulant prescriptions in the

Table 4: Subsequent prescription fills in relation to receipt of an oral anticoagulant (OAC) prescription in the emergency department

Univariable analysis

Filled

Timing and group

\section{At 6 mo}

Received OAC prescription in ED

Did not receive OAC prescription in ED

\section{At 1 yr}

Received OAC prescription in ED

Did not receive OAC prescription in ED
69.7

$<0.001$
3.4

38.9
$<0.001$

26.0
5.7

5.0

4

5.0

\section{After propensity-score weighting}

Filled

prescription, $\% \quad p$ value $\quad$ ARI $\quad$ NNT $\quad$ Died, $\%$

Note: $\mathrm{ARI}$ = absolute risk increase, $\mathrm{ED}$ = emergency department, $\mathrm{NNT}$ = number needed to treat.

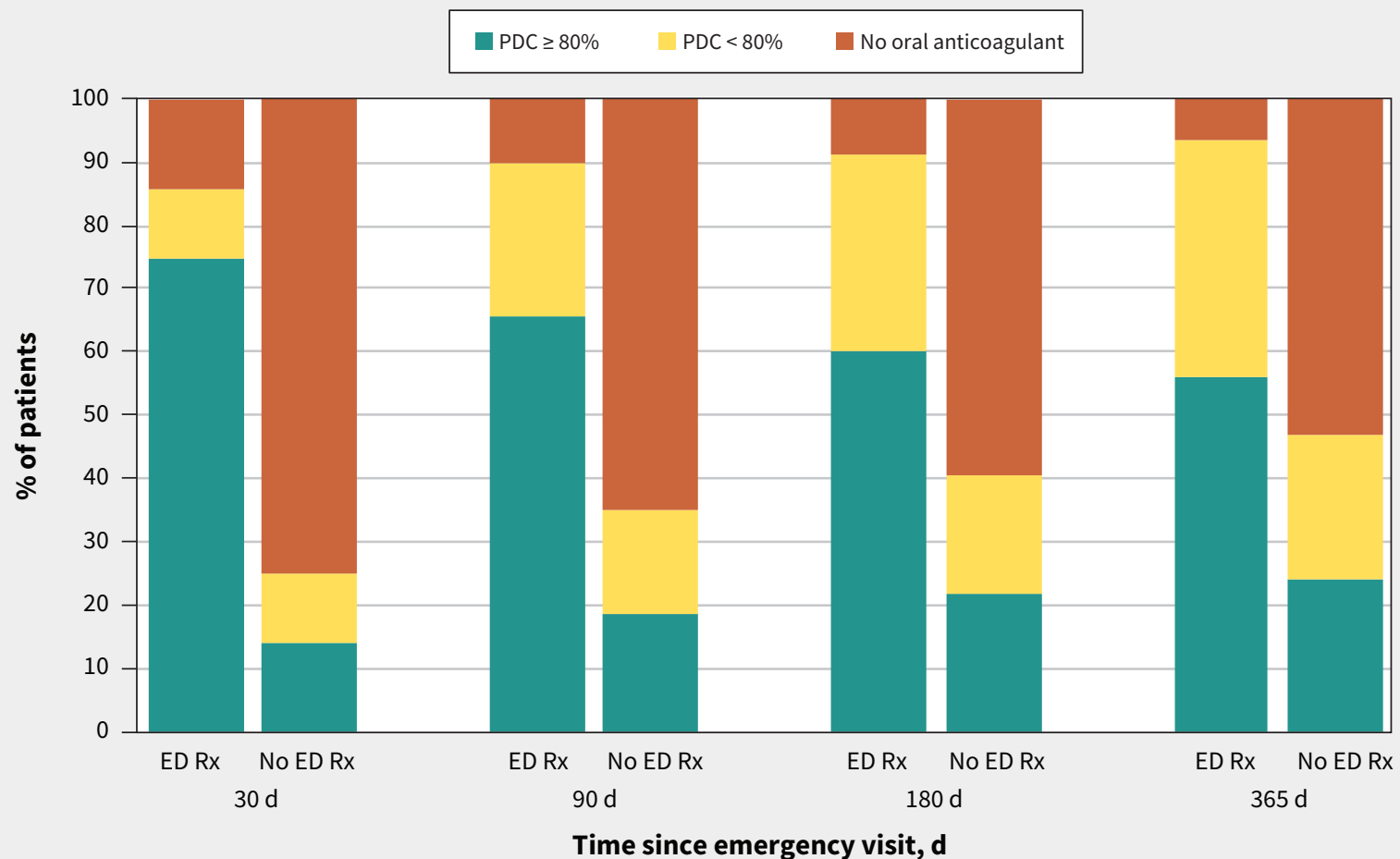

Figure 1: Among all patients, the proportion of days covered (PDC) by filled prescriptions for anticoagulant therapy for patients who received a prescription for an oral anticoagulant in the emergency department (ED Rx) and those who did not receive such a prescription (No ED Rx). 
emergency department to prevent a stroke is about 7. By comparison, the NNT for statins to prevent nonfatal myocardial infarction in patients with a history of heart disease is $39 .{ }^{45}$

There may be several explanations for our findings. Patients who receive a prescription during an emergency care episode may be more likely to fill such a prescription than patients who wait a week or a month to see their regular provider and experience no untoward event (e.g., stroke) during that delay. The finding that $75 \%$ of patients who received an emergency department prescription filled it within 2 days of discharge supports the hypothesis that the emergency department encounter is influential with patients.

A primary care provider may be more likely to continue a prescription initiated by another physician or may be reassured that another physician has initiated oral anticoagulant therapy. Among patients who received a prescription in the emergency department, there was an almost $40 \%$ absolute increase in prescription fills after follow-up with the primary care provider, relative to patients referred to longitudinal care providers to consider initiation of therapy. This effect was attenuated but still present (> 25\% absolute improvement) when internists and cardiologists provided the first follow-up appointment. Although an emergency department prescription does not guarantee subsequent refills (probably in some cases for good reason, such as a contraindication of which the emergency physician was not aware), it did substantially increase the proportion of patients with such refills. In addition, prescription fill rates after a follow-up appointment were similar among provider types for patients who received a prescription in the emergency department (56\%-59\% at 30 days), whereas the range among provider types was wider for the noprescription group (20\%-32\%). This result suggests that emergency department prescribing was associated with an increase in prescribing rates by primary care providers, to levels similar to those of cardiologists.

In a small study of 137 patients with atrial fibrillation discharged from the emergency department in Ontario, ARI was $43 \%$ for 6 -month prescription fills among patients who received a prescription in the emergency department relative to those who did not. ${ }^{27}$ Our adjusted results in a larger population were similar but attenuated (ARI 31\%).

Increasing the proportion of eligible patients receiving oral anticoagulants at the population level has been associated with a lower incidence of atrial fibrillation-related stroke; ${ }^{13}$ however, we found no reduction in deaths or strokes. Our study may have been underpowered because of low event rates. ${ }^{18}$ Subsequent discontinuation among those in the emergency department prescription group combined with initiation of oral anticoagulants in the no-prescription group would also be expected to reduce between-group differences in outcomes. Notably, prescribing of oral anticoagulants in the emergency department was not associated with an increase in major bleeding events.

Rates of oral anticoagulant initiation were much lower for patients who left the emergency department in sinus rhythm than for patients who left in atrial fibrillation, similar to results from the PINNACLE registry and other studies. ${ }^{46,47}$ This finding suggests the need to educate emergency physicians about use of oral anticoagulants regardless of atrial fibrillation type (paroxysmal v. persistent or permanent). Discontinuations and nonadherence were modestly more frequent in the emergency department prescription group; however, at all time points the proportion of patients without stroke protection was much higher in the noprescription group. The discontinuation rates may highlight other steps required to improve long-term use of oral anticoagulants, such as patient education. ${ }^{48}$

Prescribing tools can simplify decision-making for busy emergency physicians; ${ }^{49}$ however, preventive care in the emergency department may be hindered by factors such as the potential for a longer stay in the emergency department..$^{50,51}$ Importantly, with initiation of a new long-term medication, it is recommended that these patients be followed over time, to ensure the dosage is correct and adverse effects are managed. ${ }^{52}$ Because emergency physicians are not in a position to follow patients, they rarely initiate long-term medications. This may explain the low rate of oral anticoagulant initiation in our study (18.9\%; similar to other North American studies $\left.{ }^{47,53,54}\right)$. For many patients, treatment with acetylsalicylic acid may have been considered adequate: until 2012, guidelines endorsed this agent for patients with $\mathrm{CHADS}_{2}$ score of 0 or (possibly) $1 .^{55,56}$

An approach of "default short-term anticoagulation therapy" has been suggested, whereby the emergency physician prescribes an oral anticoagulant for several weeks, followed by an appointment with the longitudinal care provider, ${ }^{25}$ who decides whether to renew the prescription (based on a more thorough knowledge of the patient's medical history), provides shared decision-making and addresses HAS-BLED risk factors. ${ }^{10,25}$ If the patient does not obtain follow-up care, the prescription ends, as does the risk of bleeding. Given our results, we believe that emergency physicians should consider adapting this approach. Future work is needed to establish a reliable follow-up system that directly connects patients to longitudinal care.

\section{Limitations}

We used propensity-score methods to adjust for group differences but were unable to account for unmeasured covariables. However, in this circumstance a randomized trial is likely neither ethical nor feasible. Our study ended in 2014, and most prescriptions were for warfarin; however, warfarin use is decreasing as direct oral anticoagulant use is increasing. ${ }^{57,58}$ This shift may make it more likely that emergency and family physicians will initiate oral anticoagulation, but the impact of starting oral anticoagulation in the emergency department is unlikely to change substantially. We included all patients who qualified for stroke prevention on the basis of CHADS-65, but in the earlier years of this study, $\mathrm{CHADS}_{2}$ combined with $\mathrm{CHA}_{2} \mathrm{DS}_{2}$-VASc was recommended; ${ }^{55}$ therefore, some of the early patients would not have qualified for oral anticoagulants. There was only 1 chart abstractor, but she performed data abstraction for our previous study, which used many of the same variables and had high inter-rater agreement. ${ }^{15}$ We assessed only strokes leading to admission, because transient ischemic attacks and minor strokes are not well coded in administrative data. ${ }^{35}$ This may have resulted in an underestimation of the frequency of minor strokes and reduced our power to detect differences in stroke outcomes. 


\section{Conclusion}

In this multicentre study of patients older than 65 years with atrial fibrillation and without high-risk factors for bleeding who were discharged from the emergency department, provision of an oral anticoagulant prescription in the emergency department was associated with a $31 \%$ absolute increase in the risk of filling a prescription at 6 months, compared with referral to the longitudinal care provider to initiate this therapy. Physicians working in the emergency department should consider initiating oral anticoagulants in similar patients who are being discharged home, because this action is associated with improved use of stroke prevention long after the patient leaves the emergency department.

\section{References}

1. Chugh SS, Havmoeller R, Narayanan K, et al. Worldwide epidemiology of atrial fibrillation: a Global Burden of Disease 2010 Study. Circulation 2014; 129:837-47.

2. Go AS, Hylek EM, Phillips KA, et al. Prevalence of diagnosed atrial fibrillation in adults: national implications for rhythm management and stroke prevention: the AnTicoagulation and Risk Factors in Atrial Fibrillation (ATRIA) Study. JAMA 2001;285:2370-5.

3. Naccarelli GV, Varker H, Lin J, et al. Increasing prevalence of atrial fibrillation and flutter in the United States. Am J Cardiol 2009;104:1534-9.

4. Gladstone DJ, Spring M, Dorian P, et al.; EMBRACE Investigators and Coordinators. Atrial fibrillation in patients with cryptogenic stroke. N Engl J Med 2014;370:2467-77.

5. Risk factors for stroke and efficacy of antithrombotic therapy in atrial fibrillation. Analysis of pooled data from five randomized controlled trials [published erratum in Arch Intern Med 1994;154:2254]. Arch Intern Med 1994;154:1449-57.

6. Marini C, De Santis F, Sacco S, et al. Contribution of atrial fibrillation to incidence and outcome of ischemic stroke: results from a population-based study. Stroke 2005;36:1115-9.

7. Hart RG, Pearce LA, Aguilar MI. Meta-analysis: antithrombotic therapy to prevent stroke in patients who have nonvalvular atrial fibrillation. Ann Intern Med 2007;146:857-67.

8. Yu AY, Malo S, Wilton S, et al. Anticoagulation and population risk of stroke and death in incident atrial fibrillation: a population-based cohort study. CMAJ Open 2016;4:E1-6.

9. January CT, Wann LS, Alpert JS, et al.; ACC/AHA Task Force Members. 2014 AHA/ACC/HRS guideline for the management of patients with atrial fibrillation: a report of the American College of Cardiology/American Heart Association Task Force on Practice Guidelines and the Heart Rhythm Society [published erratum in Circulation 2014;130:e270-1]. Circulation 2014;130:2071-104.

10. Kirchhof P, Benussi S, Kotecha D, et al.; ESC Scientific Document Group. 2016 ESC guidelines for the management of atrial fibrillation developed in collaboration with EACTS. Eur Heart J 2016;37:2893-962.

11. Macle L, Cairns J, Leblanc K, et al.; CCS Atrial Fibrillation Guidelines Committee. 2016 focused update of the Canadian Cardiovascular Society guidelines for the management of atrial fibrillation [published erratum in Can J Cardiol 2017;33:552-3]. Can J Cardiol 2016;32:1170-85.

12. Laguna P, Martn A, del Arco C, et al.; Investigators in the Spanish Atrial Fibrillation in Emergency Medicine Study Group (GEFAUR). Risk factors for stroke and thromboprophylaxis in atrial fibrillation: What happens in daily clinical practice? The GEFAUR-1 study. Ann Emerg Med 2004;44:3-11.

13. Cowan C, Healicon R, Robson I, et al. The use of anticoagulants in the management of atrial fibrillation among general practices in England. Heart 2013; 99:1166-72.

14. Yu AYX, Malo S, Svenson LW, et al. Temporal trends in the use and comparative effectiveness of direct oral anticoagulant agents versus warfarin for nonvalvular atrial fibrillation: a Canadian population-based study. J Am Heart Assoc 2017;6:e007129.

15. Atzema CL, Dorian P, Fang J, et al. A clinical decision instrument for 30-day death after an emergency department visit for atrial fibrillation: the Atrial Fibrillation in the Emergency Room (AFTER) study. Ann Emerg Med 2015;66:658-68.e6.

16. Stiell IG, Clement CM, Brison RJ, et al. Variation in management of recentonset atrial fibrillation and flutter among academic hospital emergency departments. Ann Emerg Med 2011;57:13-21.

17. Barrett TW, Vermeulen MJ, Self WH, et al. Emergency department management of atrial fibrillation in the United States versus Ontario, Canada. J Am Coll Cardiol 2015;65:2258-60.
18. Atzema CL, Austin PC, Miller E, et al. A population-based description of atrial fibrillation in the emergency department, 2002 to 2010. Ann Emerg Med 2013;62:570-7.e7.

19. Healey JS, Oldgren J, Ezekowitz M, et al.; RE-LY Atrial Fibrillation Registry and Cohort Study Investigators. Occurrence of death and stroke in patients in 47 countries 1 year after presenting with atrial fibrillation: a cohort study. Lancet 2016;388:1161-9.

20. McDonald AJ, Pelletier AJ, Ellinor PT, et al. Increasing US emergency department visit rates and subsequent hospital admissions for atrial fibrillation from 1993 to 2004. Ann Emerg Med 2008;51:58-65.

21. Connolly SJ, Ezekowitz MD, Yusuf S, et al.; RE-LY Steering Committee and Investigators. Dabigatran versus warfarin in patients with atrial fibrillation [published erratum in N Engl J Med 2010;363:1877]. N Engl J Med 2009;361:1139-51.

22. Granger CB, Alexander JH, McMurray JJ, et al.; ARISTOTLE Committees and Investigators. Apixaban versus warfarin in patients with atrial fibrillation. N Engl J Med 2011;365:981-92.

23. Patel MR, Mahaffey KW, Garg J, et al.; ROCKET AF Investigators. Rivaroxaban versus warfarin in nonvalvular atrial fibrillation. N Engl J Med 2011;365:883-91.

24. Giugliano RP, Ruff CT, Braunwald E, et al.; ENGAGE AF-TIMI 48 Investigators. Edoxaban versus warfarin in patients with atrial fibrillation. N Engl J Med 2013; 369:2093-104.

25. Barrett TW, Marill KA. Anticoagulation for emergency department patients with atrial fibrillation: Is our duty to inform or prescribe? Ann Emerg Med 2013;62:566-8.

26. Atzema CL. Stroke prevention for high-risk atrial fibrillation in the emergency setting: the emergency physician perspective. Can J Cardiol 2018;34:125-31.

27. Atzema CL, Austin PC, Chong AS, et al. The long-term use of warfarin among atrial fibrillation patients discharged from an emergency department with a warfarin prescription. Ann Emerg Med 2015;66:347-54.e2.

28. National Ambulatory Care Reporting System metadata (NACRS). Ottawa: Canadian Institute for Health Information; 2016. Available: www.cihi.ca/en/types -of-care/hospital-care/emergency-and-ambulatory-care/nacrs-metadata (accessed 2016 June 2).

29. Canadian coding standards for version 2012: ICD-10-CA and CCI. Ottawa: Canadian Institute for Health Information; 2012. Available: https://secure.cihi.ca/free_products /canadian_coding_standards_2012_e.pdf (accessed 2019 Nov. 4).

30. Appendix 1: A summary of studies on the quality of health care administration databases in Canada. In: Goel V, Williams JI, Anderson GM, et al., editors. Patterns of health care in Ontario: the ICES practice atlas. 2nd ed. Ottawa: Canadian Medical Association; 1996. p. 339-46. Available: https://www.ices.on.ca/Publications /Atlases-and-Reports/1996/Patterns-of-health-care-2nd-ed (accessed 2018 Nov. 26).

31. Iron K, Zagorski BM, Sykora K, et al. Living and dying in Ontario: an opportunity for improved health information [ICES investigative report]. Toronto: Institute for Clinical Evaluative Sciences; 2008. Available: www.ices.on.ca/Publications/ Atlases-and-Reports/2008/Living-and-dying-in-Ontario (accessed 2018 Nov. 26).

32. Physician reports [website]. Hamilton (ON): Ontario Physician Human Resources Data Centre; 2014. Available: www.ophrdc.org/Public/ Reportaspx?owner=pio (accessed 2015 Feb.4).

33. Verma A, Cairns JA, Mitchell LB, et al. 2014 focused update of the Canadian Cardiovascular Society guidelines for the management of atrial fibrillation. Can J Cardiol 2014;30:1114-30.

34. Pisters R, Lane DA, Nieuwlaat R, et al. A novel user-friendly score (HAS-BLED) to assess 1-year risk of major bleeding in patients with atrial fibrillation: the Euro Heart Survey. Chest 2010;138:1093-100.

35. Hall R, Mondor L, Porter J, et al. Accuracy of administrative data for the coding of acute stroke and TIAs. Can J Neurol Sci 2016;43:765-73.

36. Beyersmann J, Gastmeier P, Wolkewitz M, et al. An easy mathematical proof showed that time-dependent bias inevitably leads to biased effect estimation. J Clin Epidemiol 2008;61:1216-21.

37. Atzema CL, Yu B, Ivers NM, et al. Incident atrial fibrillation in the emergency department: a population-based assessment of follow-up care. CMAJ Open 2015;3:E182-91.

38. Austin PC, Stuart EA. Moving towards best practice when using inverse probability of treatment weighting (IPTW) using the propensity score to estimate causal treatment effects in observational studies. Stat Med 2015;34:3661-79.

39. Austin PC. Balance diagnostics for comparing the distribution of baseline covariates between treatment groups in propensity-score matched samples. Stat Med 2009;28:3083-107.

40. ACTIVE Investigators; Connolly SJ, Pogue J, Hart RG, et al. Effect of clopidogrel added to aspirin in patients with atrial fibrillation. N Engl J Med 2009;360:2066-78.

41. The Johns Hopkins ACG System. Baltimore (MD): Johns Hopkins University; 2017. Available: www.hopkinsac.gorg (accessed 2017 May 25).

42. Beveridge R, Clarke B, Janes L, et al. Implementation guidelines for the Canadian Emergency Department Triage \& Acuity Scale (CTAS). Canadian Emergency 
Department Triage \& Acuity Scale; 1998. Available: http://ctas-phctas.ca/wp -content/uploads/2018/05/ctased16_98.pdf (accessed 2017 May 25).

43. Gomes T, Mamdani MM, Holbrook AM, et al. Persistence with therapy among patients treated with warfarin for atrial fibrillation. Arch Intern Med 2012;172:1687-9.

44. Jackevicius CA, Tsadok MA, Essebag V, et al. Early non-persistence with dabigatran and rivaroxaban in patients with atrial fibrillation. Heart 2017;103:1331-8.

45. Statins given for 5 years for heart disease prevention (with known heart disease): 83 for mortality. The NNT Group; 2013. Available: www.thennt.com/nnt/statins-for -heart-disease-prevention-with-known-heart-disease/ (accessed 2018 Nov. 26).

46. Hsu JC, Chan PS, Tang F, et al. Differences in anticoagulant therapy prescription in patients with paroxysmal versus persistent atrial fibrillation. Am J Med 2015;128:654.e1-10

47. Vinson DR, Warton EM, Mark DG, et al. Thromboprophylaxis for patients with highrisk atrial fibrillation and flutter discharged from the emergency department. West J Emerg Med 2018;19:346-60.

48. Vinereanu D, Lopes RD, Bahit MC, et al.; IMPACT-AF investigators. A multifaceted intervention to improve treatment with oral anticoagulants in atrial fibrillation (IMPACT-AF): an international, cluster-randomised trial. Lancet 2017; 390:1737-46

49. Parkash R, Magee K, McMullen M, et al. The Canadian Community Utilization of Stroke Prevention study in atrial fibrillation in the emergency department (C-CUSP ED). Ann Emerg Med 2019;73:382-92.

50. Delgado MK, Acosta CD, Ginde AA, et al. National survey of preventive health services in US emergency departments. Ann Emerg Med 2011;57:104-8.e2.
51. Kelen GD. Public health initiatives in the emergency department: Not so good for the public health? Acad Emerg Med 2008;15:194-7.

52. Prescribing drugs. Toronto: College of Physicians and Surgeons of Ontario 2012 [updated 2017]. Available: www.cpso.on.ca/policies-publications/policy/ prescribing-drugs (accessed 2019 Nov. 20).

53. Stiell IG, Clement CM, Rowe BH, et al. Outcomes for emergency departmen patients with recent-onset atrial fibrillation and flutter treated in Canadian hospitals. Ann Emerg Med 2017;69:562-71.e2.

54. Misra $\mathrm{P}$, Lang E, Clement $\mathrm{CM}$, et al. Emergency physician patterns related to anticoagulation of patients with recent-onset atrial fibrillation and flutter. J Atr Fibrillation 2013;5:645.

55. Cairns JA, Connolly S, McMurtry S, et al.; CCS Atrial Fibrillation Guidelines Committee. Canadian Cardiovascular Society atrial fibrillation guidelines 2010 prevention of stroke and systemic thromboembolism in atrial fibrillation and flutter. Can J Cardiol 2011;27:74-90.

56. Skanes AC, Healey JS, Cairns JA, et al.; Canadian Cardiovascular Society Atrial Fibrillation Guidelines Committee. Focused 2012 update of the Canadian Cardiovascular Society atrial fibrillation guidelines: recommendations for stroke prevention and rate/rhythm control. Can J Cardiol 2012;28:125-36.

57. Huisman MV, Rothman KJ, Paquette M, et al. The changing landscape for stroke prevention in AF: findings from the GLORIA-AF Registry phase 2. J Am Coll Cardiol 2017;69:777-85.

58. Tu K, Nieuwlaat R, Cheng SY, et al. Identifying patients with atrial fibrillation in administrative data. Can J Cardiol 2016;32:1561-5.
Competing interests: For activities outside the submitted work, Paul Dorian has received personal fees from Bayer and Servier as well as grants and personal fees from BMS and Pfizer, and Ratika Parkash has received grants from Pfizer, Boehringer-Ingelheim, Medtronic and Abbott as well as honoraria from Servier. No other competing interests were declared.

This article has been peer reviewed.

Affiliations: ICES Central (Atzema, Jackevicius, Chong, Ivers, Austin); Division of Emergency Medicine, Department of Medicine (Atzema), Division of Cardiology, Department of Medicine (Dorian), Department of Family Medicine (Ivers) and Institute for Health Policy, Management and Evaluation (Jackevicius, Dorian, Ivers, Austin), University of Toronto; Sunnybrook Health Sciences Centre (Atzema); Women's College Hospital (Ivers); St. Michael's Hospital (Dorian), Toronto, Ont.; Western University of Health Sciences, Pomona, Calif. (Jackevicius); QEII Health Sciences Centre (Parkash), Halifax, NS

Contributors: All of the authors contributed to the concept and design of the study, and participated in the analysis and interpretation of data. Clare Atzema and Alice Chong acquired the data. Clare Atzema, Cynthia
Jackevicius, Alice Chong and Peter Austin performed the statistical analysis. Clare Atzema drafted the manuscript, and all of the authors critically revised the manuscript for important intellectual content. Clare Atzema obtained the funding. All of the authors approved the final version to be published and agreed to be held accountable for the work. Clare Atzema had full access to all the data in the study and takes responsibility for the integrity of the data and the accuracy of the data analysis.

Funding: This project was supported by a grant from C-SPIN (Canadian Stroke Prevention Intervention Network), which was funded by a Canadian Institutes for Health Research (CIHR) Emerging Network Grant under the Institute of Circulatory and Respiratory Health. Clare Atzema was supported by a Mid-Career Investigator Award from the Heart and Stroke Foundation of Ontario (HSFO), the Practice Plan of the Department of Emergency Services at Sunnybrook Health Sciences Centre and the Sunnybrook Research Institute. Paul Dorian and Ratika Parkash were supported by the Cardiac Arrhythmia Network of Canada (CaNET) National Centre of Excellence. Noah Ivers was supported by a New Investigator Award from the CIHR. Peter Austin was supported by a Mid-Career Investigator Award from the HSFO.
Data sharing: The data set from this study is held securely in coded form at ICES. While datasharing agreements prohibit ICES from making the data set publicly available, access may be granted to those who meet prespecified criteria for confidential access, available at www.ices on.ca/DAS. The full data set creation plan and underlying analytic code are available from the authors upon request, on the understanding that the programs may rely upon coding templates or macros that are unique to ICES.

Disclaimers: The Heart and Stroke Foundation of Ontario had no involvement in the design or conduct of the study, data management or analysis, or manuscript preparation, review, or authorization for submission. This study was supported by ICES, which is funded by an annual grant from the Ontario Ministry of Health and Long-Term Care (MOHLTC). The opinions, results and conclusions reported in this paper are those of the authors and are independent from the funding sources. No endorsement by ICES or the Ontario MOHLTC is intended or should be inferred.

Accepted: Oct. 31, 2019

Correspondence to: Clare Atzema, clare. atzema@ices.on.ca 